\title{
Some results of breeding a predatory stink bug of Perillus bioculatus F. (Hemiptera, Pentatomidae) in the Republic of Moldova
}

\author{
Dina Elisovetcaia ${ }^{1 *}$, Valeriu Derjanschi ${ }^{1}$, Irina Agas'eva ${ }^{2}$, and Mariya Nefedova $^{2}$ \\ ${ }^{1}$ Institute of Zoology, Republic of Moldova, Chisinau \\ ${ }^{2}$ All-Russian Research Institute of Biological Plant Protection, Russia, Krasnodar-39, 350039
}

\begin{abstract}
The impact of insect artificial diet on the egg production of females was examined for L29 consequently generations of laboratory populations Perillus bioculatus (F.) (Hemiptera: Pentatomidae, Asopinae). Particular attention is paid to the overwintered generation, which plays a key role in the rehabilitation of the predator populations after hibernation. It was shown that with an increase in the number of laboratory generations of a predator (from L13 to L29), egg production of P. bioculatus females significantly decreases - from 16.4-35.7 to 15.0-27.5 eggs / female in terms of the total number of females in the laboratory populations. The proportion of eggs laid by females of winter generation was the lowest when feeding on Galleria mellonella larvae. Was established food preferences among the assortment of native for Republic of Moldova leaf beetles: Entomoscelis adonidis Pallas 1771, Chrysolina herbacea (Duftschmid, 1825) and C. coerulans (Scriba, 1791). P. bioculatus imago overwintered generation refused to feed on E. suturalis larvae and imago, probably because of the isoquinoline alkalods contained in the hemolymph of the leaf beetle. Studies have shown that supplementary feeding with imago of E. adonidis, C. herbacea and C. coerulans increases from $8.3 \pm 0.5 / 50$ till $11.2 \pm 0.7 / 104$ per day / total egg production of $P$. bioculatus females of the overwintered generation.
\end{abstract}

\section{Introduction}

For modern organic farming using natural entomophagous will always be an excellent attractive idea. With that in mind, the discovered of two spotted stink bug Perillus bioculatus (F.) (Hemiptera: Pentatomidae) in Europe caused a great resonance in the scientific world $[1,2,3,4,5,6]$. Adaptation on the European continent of two spotted stink bug, which is a predator of the most important and economically significant invasive species - the Colorado potato beetle (Leptinotarsa decemlineata Say), puts forward new requirements for laboratory breeding of the entomophage in new conditions [7].

\footnotetext{
*Corresponding author: dina.elis.s@gmail.com
} 
One of the key points of laboratory breeding is the diet of predators. Work on the study of the influence of artificial nutrient media for the predatory Asopinae bugs, begun in the last century, continues at present $[8,9]$. The main question is devoted to studying the development of all ontogenetic stages of the predator P. bioculatus, as well as the egg production and fertility of females, when fed by the other species of insects or artificial diets. It is also known that some imago of P. bioculatus can overwinter twice [10]. Thus, interest in egg production of females stink bugs after hibernation is significantly increased. Replacing the host, the L. decemlineata, with both other species of insects and artificial nutrient media, inevitably leads to a decrease in the fertility and egg production of $P$. bioculatus females [11]. In laboratory breeding of stink bugs on an artificial diet, some authors explain the reduction in egg production by females not only as a protein deficiency, but also by the absence of chemical or behavioral signals that would confirm the presence of live prey [8].

Despite the great interest in breeding P. bioculatus in the laboratory for its subsequent release against the Colorado potato beetle, there is still insufficient information on which phytophagous species of insects in Europe could replace or supplement the well-known Lepidoptera larvae. The analysis of scientific literature data on the food preferences of $P$. bioculatus showed that the predator developed well when it was fed by larvae Calliphora erythrocephala Mg., Ephestia kuehniella Zell. but Tenebrio molitor L. and some others [9]. Specification of the species of host insects for the predator is important, because various defoliator insects can accumulate in the hemolymph different biologically active substances (BAS). These BAS affect the development the larval stages of predatory Pentatomids, as well as on egg production and females' fertility [12].

In North America there are a greater number of leaf beetles of the tribe Doryphorini, which can be included in the diet of a predator. In countries where not long ago was found $P$. bioculatus, only a few can boast of the presence of an additional feed base in the form of representatives of the tribe Doryphorini. This is Zygogramma suturalis F. and Zygogramma bicolorata Pallister, which were respectively imported and acclimatized as herbiphages to Russia and India consequently $[6,13]$. And this fact greatly facilitates laboratory breeding of P. bioculatus. In the Republic of Moldova there are no leaf beetles from tribe Doryphorini, except for $L$. decemlineata, that are included in the diet of the oligophages.

The discoveries of the two spotted stink bug P. bioculatus in Europe often only confirmed the presence of a predator; at best, they recorded its predation on a Colorado potato beetle. However, a very small percentage of research is currently being devoted to the study of alternative insect hosts. Nevertheless, some new finds of P. bioculatus on alternative hosts in new habitats for the predator inspire hope for revealing the secrets of its spread and survival in Europe and Asia [14].

We have repeatedly organized large-scale searches for additional food sources for the stink bug in our country. However, at present, the question of the survival of a predator in new conditions for him, especially after wintering, still remains open. Therefore, it is important and relevant to study the egg productivity of $P$. bioculatus females when feeding on various species of insects, which are widespread in the conditions of the Republic of Moldova.

\section{Materials and methods}

The experiments were carried out during the years 2014-2020 in the laboratory Entomology of the Institute of Zoology and in the laboratory of the State Collection of Entomoakariphages and Initial Evaluation of Biological Means of Plant Protection of the All-Russian Research Institute of Biological Plant Protection. As an object of research, laboratory populations of a predatory stink bug Perillus bioculatus Fabr. (Hemiptera, 
Pentatomidae) were used. In the Republic of Moldova two spotted stink bug P. bioculatus was introduced in the laboratory culture in 2014. Each year the laboratory populations were enriched from the natural reserves of the predator from different localities from Republic of Moldova. Basically, these were predator populations collected from potato fields from June to August in mun. Chisinau. However, in 2019, we also additionally collected a predator in the village Drasliceni, district Criuleni. After harvesting from the fields, the natural individuals of P. bioculatus (nymphs and imago) were quarantined. Ovipositions was also kept separately from laboratory to molting of the larvae (nymphs) in the imago, and only after that special marks were applied to the imago and mixed with the laboratory culture of a predator.

The insects $P$. bioculatus were kept in cages at the temperature $+26 \pm 2{ }^{\circ} \mathrm{C}$, and 16 -h day length. Nutrition was different and varied according to options, and also depended on the season. In control variants, a mixed type of food was used for culture reproduction: in the season they fed various phases of the Colorado potato beetle Leptinotarsa decemlineata Say (Coleoptera, Chrysomelidae), egg-laying, larvae and adults, in the off-season - larvae of the wax moth Galleria mellonella (Linnaeus, 1758) (Lepidoptera: Pyralidae).

We studied the following indicators: the rate of development of each ontogenetic phase of a predator, the percentage of mortality by developmental phases, predatory skills, the ability to switch (change) to different types of feed (various species chrysomelids and other insects). We also monitored mating and egg-laying of the predatory stink bug.

To grow potatoes in the winter-spring period, the jacket was cut from the tubers with eyeholes (maybe not sprouted) with a thickness of about $1 \mathrm{~mm}$ or a little more - so as not to damage the eyeholes. And, thus obtained sections, were planted in light soil - sand or a mixture of peat and sand. Flowerpots or cassettes with planted potato slices were placed in deep vessels. Once planted, the substrate was watered, and then water was refilled every 37 days only in the lower vessels. As necessary, the potatoes were cut off, part of the empty peel was completely removed and new peels with eyeholes were planted as the stems were cut. Thus, we provide a continuous conveyor for growing young potato shoots.

\section{Results and discussions}

As a result of the studies, it was found that Moldovan predator populations of the $P$. bioculatus in the laboratory conditions can easily switch to feeding by the other species of insects.

In the conditions of the Republic of Moldova, a predatory bug P. bioculatus, self adapted, was first found and identified by us in 2013. We introduced its into the laboratory culture in late summer 2014. Primarily, the two spotted stink bug was fed in laboratory conditions by the Colorado potato beetle - by eggs, larvae and adults. However, since the end of September, the L. decemlineata beetle has gone into diapause and laboratory populations of $P$. bioculatus has been switched to food by larvae of the Galleria mellonella. We tried to feed the nymphs and imago of the predator with live larvae of Lepidoptera. $P$. bioculatus hunted with pleasure, but the problem was that the G. mellonella larvae weave a cocoon from any materiasl in the cages. Therefore, we had to go along the wellknown path, and treatmentted the larvae with boiling water. Our observations showed that the predatory bugs actively fed on "scalded" larvae, however, they chose the most "dense" and less "welded" ones. It is very difficult to choose the time for dipping the larvae in boiling water. If overexposed for a split second, the material overheats and quickly deteriorates in the cages. If not kept up, some larvae remain alive and could gnaw gas in cages. When freezing larvae, we also encountered problems after thawing them. The material was sleepy, the larvae lost moisture and, as a result, turgor. Such larvae are unattractive for imago and nymphs $P$. bioculatus. Therefore, we have chosen another way 
to prepare the larvae - without heat treatment, as well as excluding freezing. Thus, the larvae remained alive, but they were deprived of the opportunity to weave a cocoon and gnaw gas in the cages. As a result, the material could remain in cages in good condition for several days. This is especially true for mass breeding in order to be able to change feed less frequently in cages.

It should be noted that feeding P. bioculatus with larvae of the Galleria is only a surrogate substitute for a complete feed of oligophagous. If the predator does not feed on its direct hosts, then the females lay fewer eggs, and the percentage of fertile eggs in the clutch decreases. And later, during molting, up to the last stage of molting in the adult, the percentage of full-fledged individuals of P. bioculatus decreases. The death of the larvae when breeding them on other, non-specific hosts, increases significantly from each molt. When one generation of $P$. bioculatus was reared, the death of the larvae from hatching to molting in imago when feeding only $G$. mellonella larvae reached 20 to $75 \%$, depending on whether the Colorado potato beetle was additionally used for feeding, as well as other species of leaf beetles.

In addition, when feeding only G. mellonella larvae, the percentage of defective individuals of $P$. bioculatus during molting is increasing - exuvium does not completely go away and insects die during molting. One of the molting defects is the attachment of exuvia residues to the third legs (most often right leg) of the insect. Also an interesting fact deformation of the tarsus of the third legs, most often on the right side. The tarsus is either elongated and does not obey of the insect, interferes with movement. In some cases, on the contrary, the leg is shortened or the third segment of the leg - tarsus - is completely absent. In this case, as a rule, the insect can move and hunt, although it can lag behind its healthy counterparts.

Deformation of imago hemielytras also occurs. In nature, this fact undoubtedly affects survival. In the laboratory, such individuals feed and live on a par with the population. During winter diapause, the percentage of death of defective individuals is at the level of the rest (healthy) of the population. However, during mating, with the available choice of other partners, individuals with defects are more often ignored. At the same time, we have noted cases of mating both males and females with hemielytra defects. Data on the number of eggs laid by females with developmental defects have so far been insufficiently accumulated by us for statically correct interpretation.

As a result of many years of research, we have revealed the dependence of the egglaying productivity of $P$. bioculatus females all generations on the species of insects as food. It was detected that when feeding larvae of the Colorado potato beetle, females of P. bioculatus the summer generations laid on average from 16.3 to 21.8 eggs per day (up to 33 maximum). Whereas when feeding the G. mellonella larvae - only from 12.0 to 13.8 eggs per day (22 maximum). For wintered generation, these indicators were significantly lower. First, from 30 to $55 \%$ of the females did not start egg laying after hibernation. Many of them copulated many times, but as a result they died without laying a single egg. The remaining $45-70 \%$ of females (depending on the overwintered generation - the largest percentage of oviparous females was among those individuals of P. bioculatus who had matured in the imago earlier - in mid-late August, the smallest percentage of fertile females was among the generations molting in the imago in late September or October-November) laid an average of 7.5-9.1 eggs per day. As a result, it was found that the productivity of overwintered females of $P$. bioculatus when feeding the G. mellonella larvae is rather low about 50-70 eggs / female in terms of fertile females, or 15.0-27.5 eggs / female in terms of the total number of females in the laboratory populations. It is noted that over three years $\left(29^{\text {th }}\right.$ generations) the egg-laying productivity has significantly decreased. So for the period from 2014 to 2017 ( $13^{\text {th }}$ generations), for the wintering generation productivity was 16.435.7 eggs / female in terms of the total number of females in the laboratory populations. 
This level (total 50-70 eggs / female) is two to five times lower than the potential egg production of females $P$. bioculatus.

Adams T.S. showed that females of $P$. bioculatus fed the artificial diet, have a low level of essential substances for the synthesis of vitellogenin. Therefore, the maturation of egg production in such females is significantly difficult [11]. The authors note that the decrease in female fertility when breeding on an artificial diet occurs usually starting from about the L1 $1^{\text {th }}$ generation $[11,15]$. We during our research also found a significant decrease in female egg-production over 7 years of laboratory breeding of a predator. Despite the fact that every year we regenerate the P. bioculatus laboratory population by supplemented individuals from potato agrocoenosis from different locations. Consequently, in order to restore the culture of P. bioculatus after hibernation, to quickly increase the required number of predators for releases to the potato fields against to the first generation of the Colorado potato beetle, it is necessary to hunt for alternative sources of lepidopteran larvae.

For this reasons, during the entire period of $P$. bioculatus breeding under laboratory conditions from 2014 to 2020 , we experimented with various kinds of predator feeds to increase the survival of larvae after hatching and to molt them in the imago, as well as to shorten the time between the emerge predator from hibernation and the beginning of egg laying in spring.

First of all, of course, it is effective to collect the adults of the Colorado potato beetle in late August-September, and put them in storage. This is possible with reduced feed consumption, photoperiod and temperature. After hibernations we combined two types of food for P. bioculatus - both the imago of the L. decemlineata and the larvae of the G. mellonella. This is important because after hibernation, the stink bugs are suppressed, and not all adults can prey on the imago Colorado potato beetle, which is well protected with "armor".

As a result of combined feeding was established that, firstly, the oviposition of the P. bioculatus began two weeks earlier compared to the Perillus diet only on the G. mellonella larvae. Secondly, the proportion of oviparous females of P. bioculatus increased significantly, and the average number of eggs laid by one female and, accordingly, the entire population increased (Table 1).

Table 1. Egg-laying productivity by females of Perillus bioculatus depending of the food

\begin{tabular}{|l|c|c|c|c|}
\hline \multirow{1}{*}{$\begin{array}{c}\text { Generation of } \\
\text { the } \\
\text { P. bioculatus }\end{array}$} & \multicolumn{3}{|c|}{$\begin{array}{c}\text { The number of eggs laid by one female P. bioculatus on average per } \\
\text { day / total, depending on the insect species as food }\end{array}$} \\
\cline { 2 - 5 } & $\begin{array}{c}\text { Gellonella } \\
\text { larvae }\end{array}$ & $\begin{array}{c}\text { G. mellonella } \\
\text { larvae+ imago } \\
\text { of the } \\
\text { L. decemlineata }\end{array}$ & $\begin{array}{c}\text { L. decemlineata, } \\
\text { egg-laying, } \\
\text { larvae, imago }\end{array}$ & $\begin{array}{c}\text { G. mellonella } \\
\text { larvae+ imago of } \\
\text { Chrysomelids } \\
\text { (Entomoscelis } \\
\text { adonidis, Chrysolina } \\
\text { herbacea, } \\
\text { C. coerulans) }\end{array}$ \\
\hline overwintering & $8.3 \pm 0.5 / 50$ & $9.8 \pm 0.6 / 70$ & - & $11.2 \pm 0.7 / 104$ \\
\hline I & $9.8 \pm 0.5 / 80$ & $15.5 \pm 0.7 / 115$ & $19.1 \pm 0.9 / 140$ & - \\
\hline II & $10.7 \pm 0.7 / 94$ & $16.8 \pm 0.8 / 130$ & $22.4 \pm 1.1 / 170$ & - \\
\hline
\end{tabular}

It should be noted that $P$. bioculatus females of summer generations lay their eggs either daily, sometimes two ovipositions per day, or one oviposition every two to three days. Females of the overwintered generation lay their eggs very nonuniformly. They can be laid by oviposition every other day; such females, as a rule, die within one to two weeks after the start of oviposition. Other females can lay eggs once every 4-7 days, such females live longer after hibernation. 
To increase egg laying after hibernation and in the early spring breeding season, we proposed different species of leaf beetles' family Chrysomelidae to laboratory cultures of P. bioculatus in different years: Entomoscelis suturalis J.Weise, 1882, Entomoscelis adonidis Pallas 1771, Chrysolina herbacea (Duftschmid, 1825) and Chrysolina coerulans (Scriba, 1791).

We had high hopes for the imago and larvae of the E. suturalis. We considered it the most suitable food for P. bioculatus because leaf beetle accumulates some alkaloids from Glaucium flavum Crantz when it feeds on these Papaveraceae plants. The second reason is that E. suturalis imago can already be found in large quantities on the plantations of the G. flavum, starting in April, when the Colorado potato beetle is not yet in the potato fields. However, most likely it is the isoquinoline alkaloids from G. flavum that served as a repellent and antefeedant signal for feeding $P$. bioculatus with the leaf beetle E. suturalis.

At the same time, when were added adults of leaf beetles E. adonidis, C. herbacea and C. coerulans in the cages with P. bioculatus, a positive reaction at a predator was detected (Fig. 1-4). prefers coleopteran insects.

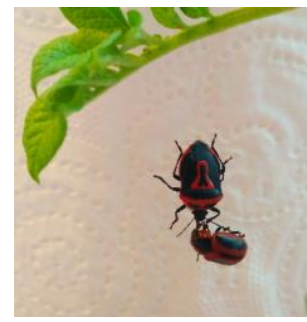

1

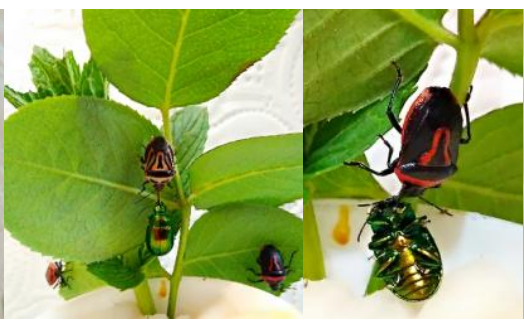

3

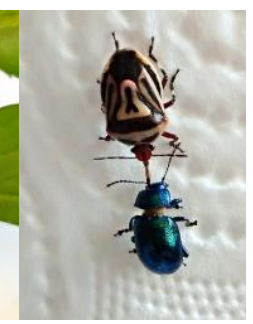

4

Fig.1. Feeding of Perillus bioculatus in the laboratory conditions with various species of Chrysomelidae leaf beetles: Entomoscelis adonidis (1), Chrysolina herbacea $(2,3)$ and Chrysolina coerulans (4)

Leaf beetles instantly attracted the attention of predator. Females of $P$. bioculatus were more active when hunting leaf beetles, than when feeding G. mellonella larvae. It was also established that the $C$. herbacea was the most popular and within 3 minutes all the added adults of the mint leaf beetle were "sorted out". So, copulating females also began to hunt at the time of adding C. herbacea bugs. Another fact cannot be ignored. Females of E. adonidis laid eggs on rapeseed Brassica napus L. (Brassicáceae) in cages. And the $P$. bioculatus females preferred to lay their oviposition in close proximity, despite the extremely small size of the eggs of the rapeseed leaf beetle. What once again shows - in nature, for its survival, Perillus bioculatus uses many species of leaf beetles. Despite the fact that predator also feeds on larvae of some species of lepidopteran, it

As a result of the introduction of an additional feed consisting of E.adonidis, C. herbacea and C.coerulans adults, egg production of laboratory P. bioculatus populations of wintering generations increased to 11.2 eggs per female / day (Tab. 1). This increase contributed to a significant increase in the first generation of stink bug. Thus, the natural populations of early spring leaf beetles of native species play a significant role in increasing the egg production of winter females P. bioculatus of the overwintered generation.

Thereby, in this study were showed that in the laboratory conditions, highest fertility can only be achieved by breeding $P$. bioculatus on its host, the Colorado potato beetle and as an alternative - immediately after hibernation in the early spring period, additionally include in the diet of P. bioculatus except lepidopteran larvae various species of available Chrysomelidae. 


\section{Conclusions}

Egg production of overwintered generations of Perillus bioculatus significantly depends not only on the photoperiod and temperature, but also on the quality of nutrition and the number of previous laboratory generations. An increase in the number of laid eggs by females of stink bug can be achieved by feeding the insects emerging from the diapause with imago of the Colorado potato beetle, as well as with adults of native species of leaf beetles, such as of Entomoscelis adonidis, Chrysolina herbacea and C. coerulans.

The researches was carried in the fundamental project 20.80009.7007.02. from State program of the Institute of Zoology.

Studies were carried out in accordance with State Assignment No. 075-00376-19-00 of the Ministry of Science and Higher Education of the Russian Federation as part of research on the topic No. 0686-2019-0009.

\section{References}

1. L. Protic, Z. Nebojsa. Acta entomol. Serbica, 17(1/2): 23-28 (2012)

2. N. Simov, M. Langourov, S. Grozeva, D. Gradinarov. Acta zoologica bulgarica. 64(3), 241-252 (2012), http://www.acta-zoologica-bulgarica.eu/downloads/acta-zoologicabulgarica/2012/64-3-241-252.pdf

3. D. Elisoveţcaia, V. Derjanschi. Oltenia. Studii şi comunicări. Ştiinţ̧ele naturii, 32(1), 67-70 (2016), http://biozoojournals.ro/oscsn/cont/32_1/11_Elisovetcaia.pdf

4. C.S. Prasad, R. Pal. International Journal of Environmental \& Agriculture Research (IJOEAR), 1(3), 9-12 (2015), https://ijoear.com/Paper-July-2015/IJOEAR-JUN-2015-1.pdf

5. V.Ya. Ismailov, I.S. Agas'eva, V.I. Kil, E.V. Fedorenko, M.V. Nefedova, E.N. Besedina. Agricultural Biology (Sel'skokhozyaistvennaya Biologiya), 54(1), 110-120, (2019), https://doi.org/10.15389/agrobiology.2019.1.110eng

6. V. Derjanschi, D. Elisoveţcaia. Oltenia. Studii şi comunicări. Ştiinţele naturii, 30(1), 67-70 (2014), http://biozoojournals.ro/oscsn/cont/30_1/16_Derjanschi_pp104-107.pdf

7. M. Kivan, T. Aysal. Turkish Journal of Biological Control (Türk. biyo. müc. derg.). 5(1), 23-29 (2014), http://www.biyolojikmucadele.org.tr/uploads/2014-1-23-29.pdf

8. E.W. Riddick. BioControl. 54, 325-339 (2009), https://doi.org/10.1007/s10526-0089171-

z,https://www.researchgate.net/publication/225564071_Benefits_and_limitations_of_factiti ous_prey and artificial_diets_on_life_parameters_of_predatory beetles_bugs and lacewi ngs a mini-review

9. M.S. Moroz. Visnyk ZhNAU, 2(56/1), 78-86, (2016)

http://nbuv.gov.ua/UJRN/Vzhnau 2016 2\%281\%29 13

10. Kh. Saulich, D.L. Musolin. Entomological Review, 92(1), 1-26 (2011) https://doi.org/10.1134/S0013873812010010,

https://www.researchgate.net/publication/257833368_Diapause in the seasonal_cycle_of stink bugs_Heteroptera_Pentatomidae from the Temperate Zone

11. T.S. Adams. Annals of the Entomological Society of America, 93, 529-535 (2009) https://doi.org/10.1603/0013-8746(2000)093[0529:EODAMS]2.0.CO,

https://naldc.nal.usda.gov/download/9584/PDF

12. W.S. Evangelista Junior, R.L. Santos, J.B. Torres, J.C. Zanuncio. Rev. Bras. entomol., 55(2), 267-271 (2011)

https://pdfs.semanticscholar.org/89d1/b393ae5f3af1c19130ae11a58114e9e7d4ce.pdf?.ga= 2.41106018.131734425.1589401137-2099302180.1585767345.

13. F. Hasan, M.S. Ansari. Archives of Phytopathology and Plant Protection, 48(17/20), 873-889 (2015) 
https://www.researchgate.net/publication/294735585_Factors_responsible for_stagespecific_mortality and_sex_ratio_adjustment_in_Zygogramma bicolorata_Pallister_on_part henium in field conditions

14. S. Tarla, G. Tarla. International Journal of Agriculture Innovations and Research. 7(3): 317-319 (2018) https://www.researchgate.net/publication/330281223 Detection_of_Perillus bioculatus F Heteroplera_Pentatomidae on a New_Host in Anatolia

15. P. Fortes, G. Salvador, F.L. Consoli. Neotrop. entomol., 40(1), 89-96 (2011) https://doi.org/10.1590/S1519-566X2011000100013 